\title{
Canvassing identities: reflecting on the acrylic art movement in an Australian Aboriginal settlement
}

\author{
Françoise Dussart
}

\section{Introduction}

In this paper I analyse two decades of Warlpiri acrylic art production in the Central Desert settlement of Yuendumu. The study of acrylic art practices reveal how painting canvases with Dreaming stories has played a crucial role in the construction of Warlpiri identities since the early 1980s. Scrutinising painters' motivations to paint Dreaming stories for sale reveals how the production of acrylics provided a site where identity politics are negotiated among generations, between genders, and among painters, artcoordinators and the Australian society at large. The act of painting has in fact provided an arena in which ever-changing and often contrary motivations and priorities have found expression between 1984 and 2004. Tracking the significance of practice, I argue, brings us closer to an understanding of the changing nature of social identity.

\section{Aboriginal acrylic at Yuendumu: a brief background}

In the early 1980s, Australian governmental policies of self-determination encouraged Northern Territory Aboriginal people to engage in various non-Indigenous art initiatives intended to counteract the erosion of Indigenous cultural identity. Of the various programs deployed to mitigate the negative effects of colonisation and forced sedentarisation, the production of acrylic art - vibrantly painted canvases manifesting public representations of Aboriginal cosmology - proved the most resilient. Indeed, within five years of the program's start-up in 1983, Central Desert Aboriginal acrylic art - 'dot painting' as it came to be known - captured the attention of critics, collectors and scholars worldwide. As other anthropologists have noted, indigenous art that makes use of Western materials cannot be understood without careful analysis of its complex post-colonial entanglements. ${ }^{1}$ Often overlooked, however, are the equally complex local negotiations among painters and their kin (as well as non-Indigenous 'advisors') - discourses and actions, which precede, accompany, and linger long after the actual production of the art. The obvious value of such analysis is rendered all the more significant when the Indigenous negotiation of art production is tracked over 
time. Indeed, by drawing on interviews undertaken between 1984 and 2004 among Warlpiri people from the settlement of Yuendumu, it is not only possible to trace the social significance of non-Indigenous media on a settlement at large, but to explore the changing nature of social identity. As we shall see, in discussing the creation of canvases, Warlpiri painters and their kin have emphasized and contested cultural, generational and gendered attributes while producing different paths to Warlpiriness; locally constituted and globally framed by colonial and post-colonial policies. As I hope to show, the shifting values and expectations associated with the creation of acrylics in Yuendumu - where I have worked for the last quarter century - mirror broader transformations in the life of the settlement.

\section{4-1986: The rise of the acrylic gerontocracy}

The history of acrylic production at Yuendumu has been well documented elsewhere, ${ }^{2}$ but the basic chronology is as follows: in a moment that valued multifaceted efforts to nurture Aboriginal self-reliance (after more than three decades of 'sedentarised' oppression) non-Indigenous residents of the settlement made countless efforts to render the Warlpiri people and other Aborigines more self-sufficient. Economic imperatives aside, there was also an ideological incentive, a joint effort by both Indigenous and non-Indigenous residents of Yuendumu to encourage a sense of Aboriginal cultural pride and self-reliance. So in late 1983, 30 of the most senior women of the settlement decided to pool their ritual knowledge to produce enough painted objects to purchase a used Toyota Land Cruiser. ${ }^{3}$ The Toyota was needed to facilitate travelling to distant sacred sites, pursue hunting and gathering as well as ceremonial activities. These women first sold their paintings to a few friends, curators and tourists. Within a couple of months, the remunerative value of these visual representations of the Dreaming (Jukurrpa) became clear. What started out as a fundraising venture quickly attracted the attention of art professionals. More ambitious canvases were subsequently commissioned and the Aboriginal women quickly gained a broader and more discriminating audience along with the vehicle they needed.

The first group of women painters - all of whom were ritually active senior 'owners' (kirda) and 'managers' (kurdungurlu) of the Dreaming - oversaw the public representation of their countries (ngurra) that paralleled the procedures attending ceremonially constituted representations of Warlpiri cosmology. By that I mean, that although these women (and men) generally used brushes instead of fingers, the procedure necessitated the same forms of surveillance as, say, a ritual body- or sandpainting. This meant that during the process of creation, the senior painters tended to recount Dreaming stories associated with ceremonial performances. Thus, painting became a conduit for the informal transmission of ritual information - with some caveats.

2. See Dussart 1988; Anderson and Dussart 1988.

3. Since sedentarisation in the late 1940s, Yuendumu inhabitants have produced objects that they sold or exchanged for other goods with missionaries, school teachers, shop keepers, and other government officials. However, the scale of production of acrylic paintings on canvas was much larger and more reliably sustained than any previous attempt. 
Senior painters vigilantly withheld designs restricted to the initiates. This meant that paintings often had to be modified to minimise the risks associated with unauthorised revelation of non-public knowledge. A circle might become a semi-circle; a line might replace a U-shape. Stories associated with the sanctioned designs also received constant scrutiny. In fact, the process of producing those early acrylics mirrored the ceremonial surveillance associated with ritual life. Despite the novel medium of expression, the execution of all designs had to be overseen by yawulyu-wardingki or mutumapatu - initiated ritually active senior women and their male counterparts (jujuwardingki). The painters with whom I spoke all made clear the gerontocratic structure of the canvas production: only senior owners of Dreamings had the right to direct the painting of their stories, and even then all works produced had to receive the senior managers' approval.

In March 1984, the settlement's senior men got into the act. I can pinpoint the date exactly, because I was implicated in that first exchange. A dozen ritually-active senior men, impressed by the economic potential of acrylic sales, approached me and asked for help procuring supplies necessary to produce acrylic paintings of their respective versions of Dreaming. Aware of the contentious atmosphere that surrounded the production of acrylic paintings - a tug-of-war between the genders over how to represent public versions of the Dreaming - I declined the men's request and directed them to one of my male counterparts and the settlement's Adult Educator.

By mid-1985, the senior men and women painters of the settlement had managed to secure the funds needed to keep them in paints and canvases. That same year Darwin and Sydney hosted large exhibitions that featured the paintings of the senior painters. And while the Toyota soon broke down, the paintings travelled the world. I was present at Yuendumu during these early years of the so-called Acrylic Movement - a period marked by constant and often contentious negotiations between genders and among the settlement's half dozen residential groups - and observed how the production of art redefined and, at times, strengthened the ritual life of Yuendumu. For it quickly became clear to me that the acrylic canvases, far from being the solitary action of an isolated painter, were in fact highly collaborative gestures predicated on the ritual rights and obligations of the painters and their close or classificatory kin associated with the Dreaming-stories and countries represented. The dot paintings might have displayed a single signature, in large measure to satisfy Western notions of creation - a presumption that gives new meaning to 'Dotting the I'! - but each work was inevitably the product of more than one hand. Bound by kinship, the painters acted out their social and ritual relationships during the planning, production, sale and promotion of their paintings.

At the end of 1985 the art production was institutionalised through a governmental grant that allowed Yuendumu to employ a non-Indigenous art-coordinator (known then as an art-advisor) to handle the logistical demands of production and market. A few months later, in early 1986, the senior painters of Yuendumu formed a cooperative which they named Warlukurlangu, after a Warlpiri estate owned by a residential kin group that then dominated much of the ritual and aesthetic life of the settlement.

The non-Indigenous staff of Warlukurlangu saw their obligations as two-fold: (1) to make the sales operation financially viable and (2) to promote 'cultural maintenance' ${ }^{4}$ The Warlpiri had a lengthier list of expectations. They felt art-coordinators should 
supply canvases and paints, sell paintings, act as bankers, take painters and kin on hunting and gathering expeditions, facilitate transportation of logistical activities surrounding ceremonial events, gather ochres for painting and rituals, help with the daily collection of fire wood, drive painters and kin to Alice Springs and outstations to visit relatives. In exchange, the painters agreed to paint what mattered to them the most, the Dreaming. For the painters, the art-coordinators were to serve as de facto stand-in for non-Indigenous audiences and more broadly the state. They were supposed 'to look after', 'to care' [jinamardarni] for painters and their relatives. As one painter explained early on in 1986 :

I care for my Dreaming. I care that White people see my Dreaming painted [on a canvas], so they can't take that Dreaming's country away. If they see the [painted] Dreaming, they see its potency, then they understand [that it is vital]. ${ }^{5}$

In the second decade painters were forced to accept that the burdens they had hoped to place on the art-advisor had been rebuffed - a combination of duties that would have turned the advisor into the agent of things social and cosmological. The painters were forced to accept that the market for their iconographic richness rarely extended beyond the surface of their painted practices. Perhaps the unfulfilled expectations of the painters and their kin can offer at least partial explanation for the dramatic change in the politics of production. By the end of the second decade of the Acrylic Movement, painting practices were significantly less collaborative than in the first and as we shall see painters are now expecting far less from art-coordinators and the organisation as a whole.

Between 1984 and 1986 certain production protocols took shape: senior men tended to paint with other senior men, and senior women painted with other senior women. The gender-specific separation that characterised the early months of acrylic painting evolved first into a less adamant dynamic of avoidance - whereby groups of senior men and groups of senior women would paint in and around the same building, but in discrete locations. These gender-specific collaborations generally adapted the practices undertaken during ceremonial activities; to wit, the Dreaming-stories represented on canvas were produced and monitored by the same individuals responsible for those narratives during ritual activity. By that I mean that even though the painters never perceived acrylic paintings as formal extensions of actual ritual activity, the politics of production replicated the proprietary and managerial configurations present during the ceremonially generated designs. In other words, the intercultural product expanded to include the negotiation of ritual material among initiated participants in a non-ritual context. Indeed, the early years of acrylic paintings were times for senior ritually-active men and women to reconstitute eroded relationships to one another vis-àvis the production of ritual knowledge painted for sale. The monitoring and working, through the production of public versions of Dreaming-stories that could be seen by all, fostered a meta-ritual context for production. ${ }^{6}$

4. See Wright 2000 for further insight in understanding the complex roles art-coordinators are asked to perform in art centers all over Australia, and how they cope with and resist demands issued by two main constituencies, often working at cross-purposes: Aboriginal artists and state funding agencies.

5. Personal communication 1986. 
In devising ways to create appropriate paintings for sale, the Warlpiri senior painters strengthened social and economic connections among themselves and among genders. At this juncture, the acrylic practice embodied alteration in the ways control over the creation of public knowledge was engendered. The paintbrush came to be wielded by senior Warlpiri people of both genders in ways that further complicated our understanding of their ritual world. As such, the production of acrylics embodied, in its first phase, a revivified legitimacy of both male and female seniority in matters of ritual and meta-ritual activity. It is important to emphasise here that those senior painters involved were born before sedentarisation at Yuendumu in 1948. Over three decades, the then senior Warlpiri painters had seen their social roles eroded, their land taken away, their freedom to travel and re-enact the essence of their existence - the Dreaming - discouraged. Thus, in a settlement environment where some of the traditional gendered gerontologically-constituted economic and political positions had been weakened, the phenomenon of acrylic production invigorated an engendered knowledge system that traditionally privileged seniority. ${ }^{7}$ Senior female and male painters reclaimed a small measure of their pre-sedentarised constituted social status by creating or monitoring the reproduction of modified ritual designs in the newfound medium.

Such connectedness eventually extended beyond the settlement once the painters began to receive requests to travel to major cities around the world on behalf of their culture'. Enjoying a measure of prestige beyond the confines of ceremonial events sent a clear message to their kin at Yuendumu: the painters, because of their seniority, possessed the potency and power to redeploy unrestricted Dreaming-stories, albeit publicly rendered, to a broader audience.

\section{7-1993: Exchanges between generations}

In July of 1987, Yuendumu received major commissions that necessitated female and male members from Yuendumu's most prominent residential groups to come together - as they often did during ritual performances - and paint gender-specific canvases. The external impact of that undertaking has been analysed elsewhere. ${ }^{8}$ Here I would like to limit my observations to motives articulated by painters. Although non-Indigenous recognition had its place in the decision to accept the major cross-gender commission, equally important was the desire on the part of the senior painters to entice younger kin to commit to the socially and spiritually demanding 'business' of representing the Dreaming. The senior painters of both genders hoped that the commission would intensify a younger generation's commitment to those cosmological obligations that were part and parcel of the replication of the Dreaming. Some scholars have observed how acrylic painting or video have been deployed to 'preserve' culture, ${ }^{9}$ others such as Terry Turner, ${ }^{10}$ Faye Ginsburg and Fred Myers (this volume) and Melinda Hinkson ${ }^{11}$ have argued that through the circulation of media (including acryl-

\footnotetext{
Dussart 1999.

See also Myers 1986, 1994.

See Dussart 1999, 2000.

See for example Michaels 1987.

10. Turner $1990,1992$.

11. Hinkson 2004.
} 
ics), Aboriginal people reconstitute themselves and their future. This is exactly what senior painters had in mind when coaxing younger kin to help with the commissioned works. Clearly, acrylic painting was becoming a site of negotiations for the reestablishment of socialities between the young and the old. Senior painters, drawing on their repertoires of negotiations and valuations, hoped to readjust through acrylic paintings the obligations of younger kin towards the Dreaming and the land as well as intergenerational ritual obligations. By no means unique to Yuendumu, older members' concerns with the erosion of traditional cosmological obligations and ideas about young people's social spaces were met with resistance by their younger relatives who did not want to embrace notions of 'preservation' and who, in the first decade, reconstructed themselves away from the painting of acrylics themselves, as we shall see below. ${ }^{12}$

I was present in the settlement when the Warlpiri received news of the lucrative and prestigious commission from the South Australian Museum in Adelaide. Under time pressure to execute the paintings, senior painters decided to broaden the circle of painters to include younger members of their respective residential groups. Despite the mounting pressure on these younger members, few non-senior residents of the settlement answered the call. The young would-be recruits, generally between 10 and 25 years of age, found little attraction in the overtly tedious task of 'dotting' (filling in) the interiors of the canvas. Furthermore, they resisted all arguments that focused on the spiritual benefits that would accrue to those helping to produce ritual designs. Any hopes held by senior painters to strengthen or reconfigure their relations with younger kin fell on deaf ears generally. The situation was not helped by external expectations that accompanied the commission; art critics and curators were quick to note that acrylics could only be properly performed by senior kin with 'authentic traditional knowledge'. Painting practices became essentialised as 'old people's' activities within and beyond the settlement.

At the outset the settlement's senior painters saw the commission, and acrylic painting generally, as a means of addressing a number of cosmological concerns. To counteract the lack of interest in ritual matters by young Warlpiri people, they hoped to include younger residential kin in the major assignments as a means of creating a nonthreatening milieu in which ritual knowledge could be transmitted inter-generationally. Concomitantly, the senior painters focused on safeguarding propriety while deepening the ritual knowledge of their kin, actions they hoped would serve as a prelude to the nurturance of the Jukurrpa in more restricted, non-public domains. The commission offered the promise of allaying a growing fear among the settlement's senior members that ritual life was 'not as strong as it used to be'. But was this hybridised publicly produced medium ideally suited for such pedagogic and ceremonial motives? It turned out that it was not. The young kin rebuffed the entreaties of their senior kin, whose proposals and expectations were perceived as overbearing (bossy) and ignorant of young people's interests and lives.

12. See similar issues raised in the late 1970 s by famous Yolngu painter Narritjin, discussed in Morphy, Deveson and Hayne 2005. 
But what exactly was at stake during these negotiations between younger and senior Warlpiri with regards to the canvases? What was being brokered? How did the inter-generational resistance express itself? Perhaps two brief passages taken from my field notes of the period will clarify the tensions.

The first exchange took place in summer of 1987. I spoke at length with the teenage sister of a prominent senior female painter who was pressuring the young woman, whom I will call Kate, to help with the big commissions: ${ }^{13}$

FD: Do you know what your big sister is painting?

Kate: Yes that's my country, that's my Dreaming.

FD: Do you know the story?

Kate: Yes. But I cannot really tell it to you. She knows it, she [my senior sister] can tell it to you.

FD: Have you seen many painted versions of your Dreaming?

Kate: Yes I have seen lots of canvases, all the same you know.

FD: Can you paint it?

Kate: My sister can show me. She is a strong and active ritual performer.

FD: Do you want me to give you a small canvas and paints?

Kate: I can't paint. I need her permission you know. This stuff belongs to senior people, you know, I am a bit scared .... The Dreaming is really powerful. My sister - she knows the Dreaming, she is powerful, she can sing it. You know I am scared of all these old people getting together and painting. I sit here because I have close relatives here. They work with lots of powerful things from the Jukurrpa. You know it's like those yawulyu [women's ceremonies], I do not go unless she takes me there. That's all old people's stuff, juju [powerful restricted ritual and knowledgel. I don't like old people stuff.

As the exchange above shows, the knowledge ${ }^{14}$ of the Dreaming was not in play; rather, it was the representation of that knowledge, as well as the status that accrued with it, that caused Kate to resist the petitions of her elder kin. For with the rights to make manifest the Dreaming, came power, and with power, came responsibility. Kate demurred, preferring to avoid the dangers and burdens that accompanied the visual representation of a Dreaming. Indeed, she declined to enter the ritual world more generally since she perceived that world to be one rife with obligations. She did not want to have the responsibilities to control the iconographic representations of her Dreamingstories. Manifesting an adolescent ennui and rebellion, common in many societies, she resisted 'old people's stuff'.

And how did the 'old people' react to Kate's rejection? I spoke with a number of senior painters to find out. Their reactions illuminated various aspirations and dissatis-

13. Kate requested anonymity if I were to publish this exchange.

14. A person is said to 'know the Dreaming' when he or she can reenact itineraries of ancestral beings and travel to the sites. In other words, a knowledgeable person can sing, dance and paint specific Dreaming-stories for which she or he is responsible through kinship and residential affiliations. 
factions among the ritual leaders of Yuendumu. Three comments represent the general sentiments of those senior residents:

Painter A: When we are all dead, [Kate] will remember. She'll remember we taught her.

Painter B: She sleeps around too much, even with men who are not fully initiated, she'll learn nothing. She thinks differently than us senior ritual women [yawulyuwardingki]. She does not help me with my paintings [as she should if she were a good kin], she does not sit and listen to ritual songs. She wonders around the settlement or goes off into town. She's got different ideas. Maybe she is scared.

Painter C: We do not know how young people think. They have different ways to think. Maybe they'll learn. Maybe not.

In the end, despite their heartfelt desire (and the assistance of art-coordinators) the senior painters had only limited success in involving their younger kin in the production of acrylics. The painting itself was hard enough to execute, but when coupled with the demands of learning the ritual narratives and obligations associated with the designs, the challenge proved overwhelming. Ultimately, the senior painters painted the canvases (and many subsequent works) on behalf of younger kin, who at times sold the works under their names. While this transaction satisfied various perceived obligations the senior painters felt vis-à-vis their younger relatives, it misrepresented the true nature of the painter's output. It effectively inverted the 'school of' notion common to, say, Italian Renaissance art, by broadening attribution to younger kin when it was in fact only the senior painter who had a hand in painting the work.

The tug-of-war that characterised the early negotiations between genders eventually spilled over into inter-generational tussles. Consider, for example, this emblematic exchange between a senior painter and her fifteen-year-old granddaughter:

Senior Painter: Look granddaughter, this is your father's country, this is your place. You are kirda [owner] for it. You can paint that Dreaming. This is what you have to do. [She hands a sketch of a Dreaming design to her kin.]

Granddaughter: I am too busy, I do not know how to do that. You do it for me. You look after me.

Three days later the granddaughter sold a painting under her own name to the art-coordinator even though the work had been painted by the grandmother. Whether or not the art-coordinator was aware of the true source, she praised the granddaughter and provided an advance of the painting's actual sale. When I asked the putative painter about the transaction, she beamed and said, 'My grandmother is a good kin. She always looks after me properly. She cares for me.' This explanation is used to emphasize the importance to fulfil kinship obligations redefined in a world under assault. In other words, the senior painter had amply satisfied her kinship obligations, as grandparents are de rigueur more lenient, by providing the teenager granddaughter with a painted canvas for sale.

The response is telling on a number of levels. It speaks to the complicated nature of attribution and its relationship to kin obligation. It also highlights that absence of the kind of master/student relationship documented among Yolngu painters from Arnhem Land. ${ }^{15}$ And whereas it might be tempting to conjecture that the Yolngu tradition of 
producing art - mainly in the form of bark paintings - is the result of a longer period of inter-cultural engagement, the circumstances in Yuendumu suggested a diminishing, rather than strengthening, of the intergenerational ties through the production of art. Matters were not helped by the external political changes that inevitably affected the economic circumstances of settlement life, the production and promotion of acrylic paintings and painters.

\section{Shifting values: painting acrylics between 1994 and 2004}

By the early 1990s governmental social programs that previously encouraged selfdetermination were replaced by the harsher policies of conservative parliamentarians in control of Australia's welfare policies. Their heavy-handed economic mandates of Aboriginal self-sufficiency trickled down to art-coordinators who were under increasing pressure to make the painter's cooperative financial viable. This only compounded the growing alienation among some of the ritually active painters, who ultimately chose to redirect their social capital away from the production of acrylic painting. The frustration of these erstwhile painters is best captured by Dolly Nampijinpa, Aboriginal chairwoman of Warlukurlangu until her death in 2004, who responded as follows when I asked, in July 1997, if she missed producing acrylics when she wanted to:

Painting is stressful. They [art-coordinators] sell our paintings sometimes, but for too little, now. Not like before, at the beginning. They probably steal from us. Maybe we [you and me] should not have started. Also there's too much stress with kin, too many demands are made on us the painters by White people, too many demands from our relatives for money we do not get. One day [the art-coordinator] wants me to paint, one day she says nothing. I am tired with the whole lot of them. And my grandchildren, they all want to paint canvases for Warlukurlangu, but they are ignorant, so I have to help them so they can get some money from Warlukurlangu. I have to look after my grandchildren. That's all we get from them [art coordinators] - money! They do not take me anywhere when I need to, they do not look after me properly, but they should because I am the chairwoman. Sometimes, they lend me money, but they do not look after me. That's not right. Only old people knowledgeable in the ritual ways should be given canvases. Young people can paint only if we make sure what they do is proper. The young ones, we can help them if we decide to help. They [art-coordinators] ask any young people to paint, but that's not right. They're [young painters] rubbish, they know nothing. They learn nothing like that, they get a sketch from a relative, paint it quick, that's it. They learn nothing. Nothing.

Another senior painter who abandoned acrylic, broadened the indictment:

I am sick of painting canvas. For whom? White people? I do not care for White people. They do not care for me. I have another job now, I work for kids who sniff petrol. I do not need Whites to know about the Dreaming. Warlukurlangu people [art-coordinators] they only like some painters. They do not help everyone at Yuendumu, only some painters. But the Dreaming-stories they belong to all, not just the painters, we can all paint them. Art-coordinators should help everyone. They did not help me to go to my relatives' funerals. I was really upset with them. They did not help me really with anything, I helped them, I painted canvases for

15. See Morphy 1991; Taylor 1996. 
exhibitions when they asked me to. I am not anymore. I want to care for the sniffing-petrol mob, not White people.

More mildly, almost wistfully, a third senior painter recently observed:

I paint [with my spouse] now, in my camp. Not like at the beginning. I can hear the Dreaming, I can follow it by myself. We all paint by ourselves now. No one is boss. I am boss for myself.

The responses of these painters - manifesting various degrees of alienation and nostalgia - both vis-à-vis art-coordinators and kin resistant to satisfying inter-generational obligation - is of course not unique to Yuendumu. ${ }^{16}$ In the end, the painters quoted above redirected much of their energies away from painting and back to ritual, as a means of maintaining the Jukurrpa and the social cohesion of their residential groups.

Some senior painters made a less radical break from the acrylic movement. In fact, there are still a handful of senior painters who attempt to maintain the original spirit of the art movement - perceiving their work as the intercultural manifestation of a powerful Indigenous cosmology. But they are an exception. In the last decade most Warlpiri painters have taken a more pragmatic (or at least less spiritual) view of the enterprise abandoning both the collaborative kin-based oversight that characterised the early years of production, as well as the rhetorical discourse that invoked the promise of intercultural appreciation. More and more of the painters are producing works divorced from the social networks that had once sanctioned the designs. There are a far greater number of individual painters at work - an independence entirely divorced from the structure of collaboration that informed the earlier years of practice. That said, it would be simplistic to conclude that the emergence of the individual marks the death-knell of the social networks defining Yuendumu Warlpiriness. Rather, the current diversity of motives and methods behind the making of public art in Yuendumu manifests and contributes to the intensely heterogenous nature of post-colonial Aboriginal settlement life today.

By the mid-1990s, three main groups of painters constituted the sources for acrylic art in the settlement. The first group included original painters - mostly senior ritual business men and women from Yuendumu's three most prominent residential groups - who continued to produce art as they had in the past, but with little or no expectation for positive social dividends. These painters increasingly limited their production oversight often only to their spouses or close senior siblings.

The second group was made up of originally active painters, but these painters were more vocally disappointed by the social failures in evidence at the end of the first decade of production. As such, they advocated a more dynamic approach to problems such as drug addiction, low literacy, and exodus of young people to more urban centres - an approach that included art initiatives targeted at young at-risk relatives.

The third and final contingent of new painters was drawn from less prominent, ritually-marginal residential groups - individuals often recruited by various non-

16. See for example Merlan 1998; Austin-Broos 2003. 
Indigenous art-coordinators seeking ways to expand and find 'new blood' for a difficult market, unconcerned with ritual configurations.

It would be misguided to suggest that any of these three groups of painters sustain the level of intensity that was present in the first decade of the movement. Most of the original painters have either passed away or have dramatically scaled back their inter-cultural representations of the Dreaming that use the medium of acrylic. The motives behind this decision are multiple: a desire to focus on the strengthening and revitalisation of settlement and pan-Aboriginal ritual life; a resistance to the stresses that come with the production of art, and the funds generated by it; and a need to respond to more pressing issues of younger at-risk kin.

\section{Connecting the dots: final reflections on Aboriginal acrylic art}

In the first decade of the so-called Acrylic Movement, painters at Yuendumu created acrylic artwork that mirrored the patterns of ritual obligation in evidence during more traditional manifestations of ceremonial activity. To paint the Dreaming was to reenact and reinvigorate its ritual potency and, by extension, a means of tightening the social networks of the settlement. The burdens of ownership and managerial oversight - the kirda/kurdungurlu relationship central to the maintenance of ritual obligation strengthened through the gender-specific collaborations of senior ritual leaders willing to paint public versions of their Dreamings. As such, the first decade of acrylic art movement (1984-1994) was marked by a renewal of correlative kinship authority. Senior men and women actively involved in the ritual life at Yuendumu looked to the production of acrylics as a way of strengthening the learning of what should matter to Warlpiri people - their connections to the Dreaming, the land and their kin - and the senior painters' places in sustaining more traditional ways and beliefs. Additionally, the settlement generally felt a rare sense of external affirmation thanks to the international attention the canvases stimulated. Travel to venues beyond the settlement, to events that celebrated the rich and seemingly robust iconography of the Central Desert cultures provided a fleeting sense of importance, though a consequential social sense of stress accompanied the non-Indigenous acclaim. In short, the acrylic canvases, as negotiated acts of translation, reconfigured both intra- and inter-cultural social relations; both painters and audience were transformed by the exchange.

But by 1994, the tenor of acrylic art production had changed. Increasingly, the Warlpiri resisted the intercultural potential of the medium, despite the encouragements of the non-Indigenous art-coordinators. The second decade of the movement was marked by less productive tensions - conflicts of an intergenerational nature. It soon became clear that there was a growing divide between the senior painters who had spearheaded the movement, and younger kin resistant to the prospect of satisfying the ceremonial obligations that came with the production of the art. The presence of the artcoordinators did not help matters. Non-Indigenous intermediaries dealt with external pressures that compelled them first to 'preserve' culture, and later to make it more economically viable through a more intensely commercialised sale of acrylics. They could only turn a blind eye to the social networks that had previously determined the manner in which the visual iconography of the Warlpiri would find public expression. 
In absolute economic terms, the acrylic movement is now perhaps more robust than ever, but this increase in commercial success has come at a price. The cross-gendered and gerontologically-constituted oversight is no longer guiding its production.

Much has been written about the function of intercultural visual media within the Indigenous social sphere. Some might argue that these media serve as overt expressions of a traditional culture translated into a post-modern medium. This 'preservationist' perspective is countered by the theories of other social scientists who perceived in the translated visual acts of indigenous cultures an attempt - generally positive in its results - to reconstitute indigenousness in ways that bolster the social and political strength of a community under assault. But when it comes to the Aboriginal acrylics produced in the Central Australian Desert, a third hypothesis must be entertained. By taking the measure of change in the production of canvases over 20 years, it is necessary to acknowledge the dynamic transformations of the very nature of the exchange and production of artwork. And in this metamorphosing negotiation it is possible to identify the broader more profound negotiations of identity that have informed and shaped the social and economic identities of the painters and their relatives. In other words, although the subject matter of the canvases painted since 1984 has changed little, the social structures of the canvas-makers have been anything but static. Yet it would be wrong to suggest that the acrylic painting is a mere reflection of the erosion of the social structures associated with the traditional ceremonial life of the settlement. The act of painting has in fact provided an arena in which ever-changing and often contrary motivations and priorities can find expression. Painters of acrylics at Yuendumu are shaping new values associated with the production of Aboriginalities less tethered to traditional notions of ritual prestige, to residential group membership, and to expectation from the Australian society at large. Yuendumu in the early twenty-first century is a settlement buffeted by the competing pressures of post-industrial non-Aboriginal market forces and the resilient residues of an egalitarian ethos that once found vibrant expression in ceremonial activity.

\section{Acknowledgements}

I want to thank all the Yuendumu painters and their kin for sharing their stories and helping me understand what acrylic canvases meant to them. I owe a special debt to Molly Nampijinpa, Rosie Nangala, Dolly Nampijinpa, Judy Nampijinpa, Jack Jampijinpa, Paddy Japalajarri and Paddy Jupurrurla for their support. I also want to thank Nancy Munn and two anonymous readers for their comments on earlier drafts.

\section{References}

Anderson, Christopher and Françoise Dussart 1988, 'Dreamings in acrylic: contemporary Western Desert art', in Peter Sutton (ed), Dreamings: art from Aboriginal Australia, Braziller Publishers, New York: 89-142.

Austin-Broos, Diane 2003 'Places, practices, and things: the articulation of Arrernte kinship with welfare and work', American Ethnologist 30(1): 118-135.

Dussart, Françoise 1988, 'Women's acrylic paintings from Yuendumu', in Margie West (ed), Inspired dream, Queensland Art Gallery, Australia, Brisbane: 35-39.

- $1999^{\prime}$ What an acrylic can mean: the meta-ritualistic resonances of a Central Desert painting', in Howard Morphy and Margo Smith Boles (eds), Art from the land, The 
University of Virginia and Kluge-Ruhe Aboriginal Art Collection, Charlottesville: 193-21.

- 2000, The politics of ritual in an Aboriginal settlement: kinship, gender and the currency of knowledge, The Smithsonian Institution Press, Washington.

— 2006, 'Why media matters?', in F Dussart (guest ed), Media matters: representations of the social in Aboriginal Australia, Visual Anthropology Review, 21(1\&2): 5-10.

Johnson, Vivien 2004, Dreaming of the desert: Aboriginal dot paintings of the Western Desert, South Australia State Government Publications, Adelaide (Hardcover).

Hinkson, Melinda 2004, 'What's in a dedication? On being a Warlpiri DJ', The Journal of the Australian Anthropological Society 15(2): 143-162.

Merlan, Francesca 1998, Caging the rainbow: places, politics and Aborigines in a north Australian town, University of Hawai'i Press, Honolulu.

Michaels, Eric 1987, 'Western Desert sandpainting and post-modernism', in Yuendumu doors, Warlukurlangu Artists, AIAS, Canberra: 133-43.

Morphy, Howard 1991, Ancestral connections: art and an Aboriginal system of knowledge, Chicago University Press, Chicago.

Morphy, Howard, Pip Deveson and Katie Hayne 2005, The art of Narritjin, CD-ROM, Canberra, ANU E-Press.

Myers, Fred 1986, Pintupi country, Pintupi self, Smithsonian Institution Press and Australian Institute of Aboriginal Studies, Canberra.

— 1994, 'Culture making: performing Aboriginality at the Asia Society', American Ethnologist 21(4): 679-99.

- 2002, Painting culture: the making of an Aboriginal high art, Duke University Press, London.

Taylor, Luke 1996, Seeing the inside, Clarendon Press, Oxford.

Turner, Terrence 1990, 'The Kayapo video project: a progress report', Revue de la Commission d'Anthropologie Visuelle, Université de Montréal.

— 1992, 'Defiant images: the Kayapo appropriation of video', Anthropology Today 8(6): 5-16.

Wright, Felicity 2000, 'The art and craft story', Volume 1 Report, Desart Inc. and ATSIC, Canberra. 